\title{
Efficacy of tiotropium-olodaterol fixed-dose combination in COPD
}

\author{
This article was published in the following Dove Press journal: \\ International Journal of COPD \\ 13 December 2016 \\ Number of times this article has been viewed
}

\section{Eric Derom \\ Guy G Brusselle \\ Guy F Joos}

Department of Respiratory Medicine, Ghent University

Hospital, Ghent, Belgium
Correspondence: Eric Derom

Department of Respiratory Medicine, Ghent University Hospital - 7 K 12 IE,

185 De Pintelaan, Ghent 9000, Belgium

Tel +32 93322359

Fax +329332 234I

Email eric.derom@ugent.be

\begin{abstract}
Tiotropium-olodaterol, formulated in the Respimat soft-mist inhaler, is an inhaled fixed-dose combination (FDC) of a long-acting muscarinic antagonist (LAMA) and a longacting $\beta_{2}$-agonist (LABA), commercialized under the name of Spiolto or Stiolto. The efficacy of tiotropium-olodaterol 5-5 $\mathrm{g}$ g once daily in adult patients with COPD was documented in eleven large, multicenter trials of up to 52 weeks duration. Tiotropium-olodaterol 5-5 $\mu \mathrm{g}$ not only improved spirometric values to a significantly greater extent than placebo but also resulted in statistically significant beneficial effects on dyspnea, markers of hyperinflation, use of rescue medication, health-related quality of life, and exercise endurance. Improvements exceeded the minimal clinically important difference (MCID) for forced expiratory volume in 1 second $\left(\mathrm{FEV}_{1}\right)$, dyspnea, and quality of life. Differences between tiotropium-olodaterol 5-5 $\mu \mathrm{g}$ and the respective monocomponents were statistically significant for $\mathrm{FEV}_{1}$, dyspnea, markers of hyperinflation, use of rescue medication, and health-related quality of life, but did not reach the MCID. However, dual bronchodilatation significantly increased the number of patients who exceeded the MCID for dyspnea and quality of life. Moreover, tiotropium-olodaterol 5-5 $\mu \mathrm{g}$ was significantly more effective than salmeterol-fluticasone (FDC) twice daily at improving pulmonary function. Differences between tiotropium-olodaterol and other LAMA/LABA FDCs were not observed for $\mathrm{FEV}_{1}$ or other efficacy markers. Therefore, tiotropium-olodaterol is a valuable option in the treatment of COPD patients who remain symptomatic under monotherapy.
\end{abstract}

Keywords: COPD, bronchodilatation, dyspnea, exacerbation, exercise tolerance, LABA, LAMA, spirometry

\section{Introduction}

COPD is a preventable and treatable disease characterized by persistent airflow limitation caused by smoking and/or exposure to noxious gases. This disease is characterized by chronic and progressive breathlessness, cough, sputum production, and reduced exercise tolerance, punctuated by episodes of acute worsening of symptoms needing additional treatment and possibly emergency or hospital care. This all eventually leads to reduced activities of daily living and poor quality of life. COPD is not curable, and represents a major cause of morbidity and mortality with a considerable economic and social impact. ${ }^{1}$

COPD results from persistent pathologic abnormalities in the small airways, most often associated with parenchymal destruction, which are both progressive in nature and lead to an annual decline in forced expiratory volume in 1 second $\left(\mathrm{FEV}_{1}\right)$ that is faster than normal. ${ }^{2-6}$ Small-airway disease (obstructive bronchiolitis) leads to airflow limitation and spirometric abnormalities. Parenchymal destruction and loss of alveoli (emphysema) further enhance that airflow limitation and are also responsible for an abnormal increase in static lung volumes and a decrease in forced 
vital capacity (FVC). For many years, the Global Initiative for Chronic Obstructive Lung Disease (GOLD) has used an $\mathrm{FEV}_{1}$ : $\mathrm{FVC}$ ratio of $<0.7$ to define airway obstruction in COPD patients and classified them into four stages depending on their postbronchodilator $\mathrm{FEV}_{1}$ value. The new GOLD COPD classification distinguishes four different patient categories, A-D, according to symptoms, degree of airflow limitation, and exacerbation history. ${ }^{1}$ The management of COPD consists essentially of smoking cessation, reduction of occupational risk factors, influenza vaccination, promotion of physical activity, pulmonary rehabilitation, and treatment with bronchodilating and anti-inflammatory medicines. ${ }^{1}$

\section{Scientific and clinical rationale for dual long-acting bronchodilatation in COPD}

In COPD, airway obstruction is partially reversible, being regulated by the parasympathetic and sympathetic pathways. Although the major part of this reversible component is believed to be cholinergic in nature, the activation of $\beta_{2}$-adrenoceptors, which are abundantly present on human airway smooth-muscle cells, will stimulate adenyl cyclase activity and contribute to smooth-muscle relaxation. Consequently, combining $\beta_{2}$-agonists and muscarinic antagonists is a logical option, not only because a muscarinic antagonist can reduce the bronchoconstrictive effect of acetylcholine but also because $\beta_{2}$-agonists reduce the release of acetylcholine, and amplify in that way the bronchodilatation elicited by direct stimulation of the $\beta_{2}$-adrenoceptors on the smoothmuscle cells. ${ }^{7-9}$

Inhaled short-acting bronchodilators are widely used for symptomatic relief in COPD patients at any stage of disease severity. ${ }^{1}$ Their acute effect on $\mathrm{FEV}_{1}$ is variable, ${ }^{10}$ and the relationship between spirometric changes and symptoms is rather poor. ${ }^{11}$ Physiological studies have shown, however, that better lung emptying, resetting of functional residual capacity (FRC) at a lower lung volume, and hence a reduction in lung hyperinflation are the main mechanisms by which COPD patients derive symptomatic benefits from inhaled short-acting bronchodilators. ${ }^{12-14}$ Although maximal bronchodilatation can be achieved with a high dose of one single agent, combining two different classes of short-acting bronchodilators allows the use of lower doses, with the same efficacy results and fewer adverse effects. ${ }^{15}$

Tiotropium (TIO) was the first 24-hour long-acting muscarinic antagonist (LAMA) specifically developed for the treatment of COPD. It not only improves spirometric variables, dyspnea, and exercise tolerance ${ }^{13,16}$ but also results in significant enhancements in quality of life, improved responses to pulmonary rehabilitation, and significant reductions in exacerbation rate. ${ }^{17,18}$ Likewise, long-acting $\beta_{2}$-agonists (LABAs) yield beneficial effects on dyspnea, exercise tolerance, and quality of life to an extent that is largely comparable in magnitude with those of TIO. ${ }^{19}$ However, TIO provides better protection against exacerbations compared to LABAs, such as salmeterol (SALM) and indacaterol (IND). ${ }^{19-21}$ The GOLD strategy currently recommends the addition of a second long-acting bronchodilator for patients in GOLD COPD classes B-D to optimize symptom relief and produce greater and more sustained bronchodilatation in cases where the patient's symptoms have not improved with single agents. ${ }^{1}$

In the last few years, the number of LABAs and LAMAs has expanded, adding several agents to the first-generation long-acting bronchodilators: SALM and formoterol (FORM) as LABAs and TIO as a LAMA. These include IND, olodaterol (OLO), and vilanterol (VIL) as LABAs, and glycopyrronium (GLY), aclidinium (ACL), and umeclidinium (UMEC) as LAMAs. ${ }^{78}$ In the light of the GOLD recommendations, pharmaceutical companies have combined LAMAs and LABAs in one inhaler.

Four LAMA/LABA fixed-dose combinations (FDCs) are currently approved by the European Medicines Agency for the treatment of COPD: UMEC/VIL, TIO/OLO, and GLY/IND as once-daily FDCs, and ACL/FORM as a twice-daily FDC. Conversely, the US Food and Drug Administration has approved only UMEC/VIL and TIO/OLO as once-daily FDCs and ACL/FORM and GLY/IND as twice-daily FDCs, the latter at a reduced dose. ${ }^{22} \mathrm{~A}$ fifth FDC, GLY/FORM, is still under clinical development.

The purpose of this review is to assess the clinical effects of TIO/OLO FDCs at the recommended daily dose of TIO $5 \mu \mathrm{g}$ and OLO $5 \mu \mathrm{g}$ (TIO/OLO $5 / 5 \mu \mathrm{g}$, ie, two inhalations of TIO/OLO 2.5/2.5 $\mu \mathrm{g}$ once daily). The first part of this review focuses on differences between TIO/OLO $5 / 5 \mu \mathrm{g}$ and placebo, between $\mathrm{TIO} / \mathrm{OLO} 5 / 5 \mu \mathrm{g}$ and their respective monocomponents TIO and OLO, and between TIO/OLO $5 / 5 \mu \mathrm{g}$ and the LABA-inhaled corticosteroid (ICS) FDC SALM-fluticasone (FLU). The second part concentrates on comparisons between TIO/OLO 5/5 $\mu$ g and other LAMA/ LABA FDCs, whereas the potential clinical benefits of adding a LABA to a LAMA in the treatment of COPD are reviewed in the last part of the paper. The pharmacological properties of TIO/OLO 5/5 $\mu \mathrm{g}$ FDC will not be considered in this paper, as they have recently been reviewed in detail elsewhere. ${ }^{23-25}$ Safety issues are however briefly summarized. 


\section{Therapeutic efficacy}

Data presented in this section are based on several Phase III, multicenter, randomized, double-blind, controlled studies on the effects of TIO/OLO $5 / 5 \mu \mathrm{g}$ in patients with COPD (Table 1). In these studies, over 10,000 patients have been involved. Ten of these studies (eight of which were replicate studies) have been published as full papers in peer reviewed journals, ${ }^{26-31}$ one being available only as a European Respiratory Society abstract. ${ }^{32}$ Four studies used a crossover design, ${ }^{26,29,31,32}$ six studies were placebo controlled, ${ }^{26,28,31,32}$ and four studies compared TIO/OLO with $\mathrm{TIO}$ and/or OLO as monotherapy. ${ }^{27,30}$ In one trial, TIO/OLO was compared with the LABA/ICS SALM/FLU FDC. ${ }^{29}$ Based on findings from earlier dose-ranging studies, ${ }^{33}$ two once-daily dosages of TIO/ OLO, 2.5/5 and 5/5 $\mu \mathrm{g}$ were assessed in these trials. This section focuses only on the data of the currently recommended dosage of once-daily TIO/OLO $5 / 5 \mu \mathrm{g}$, which generally provides greater benefits than the once-daily $2.5 / 5 \mu \mathrm{g}$ dosage in terms of pulmonary function, health-related quality of life (HR-QoL) and most other COPD outcomes. In almost all studies, TIO/OLO FDC was formulated in the Respimat ${ }^{\mathrm{B}}$ soft-mist inhaler. In the first two replicate studies, ${ }^{30}$ however, TIO and OLO were inhaled separately via HandiHaler ${ }^{\circledR}$ and Respimat, respectively. In these two studies, TIO was provided at the equivalent dose of $18 \mu \mathrm{g}$ per inhalation.

In all these randomized controlled trials (RCTs), patients were aged $\geq 40$ years and were current or former cigarette smokers, with a smoking history of $>10$ packyears. Importantly, patients with a current diagnosis of asthma or other known respiratory disorders were excluded. Patients participating in these studies exhibited postbronchodilator $\mathrm{FEV}_{1}$ :FVC ratio $<0.7$ and postbronchodilator $\mathrm{FEV}_{1}<80 \%{ }^{26,27}$ or $30 \%-80 \%$ of the predicted value. ${ }^{28-32}$ An overview of the key characteristics of the TIO/OLO

Table I Completed Phase III studies comparing clinical effects of tiotropium-olodaterol fixed-dose combinations with monocomponents and/or placebo in patients with COPD

\begin{tabular}{|c|c|c|c|c|}
\hline Title & Study & $\begin{array}{l}\text { Daily treatments } \\
\text { (patients randomized) }\end{array}$ & Primary end point & Key secondary end points \\
\hline ANHELTO I+2 & ZuWallack et $\mathrm{al}^{30}$ & $\begin{array}{l}\text { OLO } 5 \mu \mathrm{g}+\text { TIO I8 } \mu \mathrm{g}(567 / 566)^{\mathrm{a}} \\
\text { TIO I8 } 8 \mathrm{~g}(565 / 566)\end{array}$ & $\begin{array}{l}\mathrm{FEV}, \mathrm{AUC}_{0-3} \text { at week } 12 \\
\text { Trough } \mathrm{FEV}_{1} \text { at week } 12\end{array}$ & SGRQ total score at week 12 \\
\hline TONADO I+2 & Buhl et $\mathrm{a}^{27}$ & $\begin{array}{l}\text { TIO/OLO } 5 / 5 \mu \mathrm{g}(522 / 507) \\
\text { TIO/OLO } 2.5 / 5 \mu \mathrm{g}(522 / 508) \\
\text { OLO } 5 \mu \mathrm{g}(528 / 510) \\
\text { TIO } 5 \mu \mathrm{g}(527 / 506) \\
\text { TIO } 2.5(525 / 507)\end{array}$ & $\begin{array}{l}\mathrm{FEV}_{1} \mathrm{AUC}_{0-3} \text { at week } 24 \\
\text { Trough } \mathrm{FEV}_{1} \text { at week } 24 \\
\text { SGRQ at week } 24\end{array}$ & TDI at week 24 \\
\hline VIVACITO & Beeh et $\mathrm{a}^{26}$ & $\begin{array}{l}\text { TIO/OLO } 5 / 5 \mu \mathrm{g}(\text { I } 39) \\
\text { TIO/OLO } 2.5 / 5 \mu \mathrm{g}(136) \\
\text { OLO } 5 \mu \mathrm{g}(138) \\
\text { TIO } 5 \mu \mathrm{g}(138) \\
\text { TIO } 2.5(137) \\
\text { PLA }(138)\end{array}$ & $\mathrm{FEV}_{1} \mathrm{AUC}_{0-24}$ at week 6 & $\begin{array}{l}\mathrm{FEV}_{1} \mathrm{AUC}_{0-12} \text { at week } 6 \\
\mathrm{FEV}_{1} \mathrm{AUC}_{12-24} \text { at week } 6 \\
\text { Peak FEV }, \mathrm{AUC}_{0-3} \text { at week } 6 \\
\text { Trough FEV, at week } 6 \\
\Delta \mathrm{RV} \text { and } \triangle \mathrm{FRC} \text { at week } 6\end{array}$ \\
\hline OTEMTO I+2 & Singh et $\mathrm{a}^{28}$ & $\begin{array}{l}\text { TIO/OLO } 5 / 5 \mu \mathrm{g}(204 / 202) \\
\text { TIO/OLO } 2.5 / 5 \mu \mathrm{g}(202 / 202) \\
\text { TIO } 5 \mu \mathrm{g}(204 / 203) \\
\text { PLA }(204 / 202)\end{array}$ & 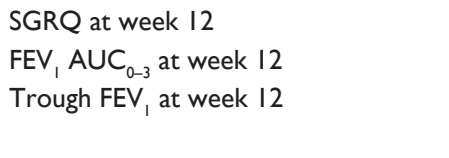 & TDI at week 12 \\
\hline ENERGITO & Beeh et $\mathrm{a}^{29}$ & $\begin{array}{l}\text { TIO/OLO 5/5 } \mu \mathrm{g}(22 \mathrm{I}) \\
\text { TIO/OLO 2.5/5 } \mu \mathrm{g}(2 \mathrm{I} 5) \\
\text { SALM/FLU 50/500 } \mu \mathrm{g} \text { BID }(2 \mathrm{I} 5) \\
\text { SALM/FLU 50/250 } \mu \mathrm{g} \text { BID }(2 \mid 2)\end{array}$ & $\mathrm{FEV}_{1} \mathrm{AUC}_{0-12}$ at week 6 & $\begin{array}{l}\mathrm{FEV}, \mathrm{AUC}_{0-24} \\
\mathrm{FEV}, \mathrm{AUC}_{12-24} \text { at week } 6 \\
\text { Peak FEV, } \mathrm{AUC}_{0-3} \text { at week } 6 \\
\text { Trough } \mathrm{FEV} \text {, at week } 6\end{array}$ \\
\hline TORRACTO & Maltais et $\mathrm{al}^{32, \mathrm{~b}}$ & $\begin{array}{l}\text { TIO/OLO } 5 / 5 \mu \mathrm{g}(139) \\
\text { TIO/OLO } 2.5 / 5 \mu \mathrm{g}(133) \\
\text { PLA (I32) }\end{array}$ & $\begin{array}{l}\text { Endurance time during constant work } \\
\text { rate cycle ergometry at week } 12\end{array}$ & $\begin{array}{l}\text { Endurance time during shuttle } \\
\text { walking test at week I2 } \\
\text { Pre-exercise IC at week I2 }\end{array}$ \\
\hline MORACTO I+2 & O’Donnell et $\mathrm{a}^{31}$ & $\begin{array}{l}\text { TIO/OLO } 5 / 5 \mu \mathrm{g}(226 / 224) \\
\text { TIO/OLO } 2.5 / 5 \mu \mathrm{g}(223 / 2 \mid 9) \\
\text { TIO } 5 \mu \mathrm{g}(227 / 218) \\
\text { OLO } 5 \mu \mathrm{g}(217 / 219) \\
\text { PLA }(222 / 2 \mid 6)\end{array}$ & $\begin{array}{l}\text { Pre-exercise IC at week } 6 \\
\text { Endurance time during constant } \\
\text { work-rate cycle ergometry at week } 6\end{array}$ & \\
\hline
\end{tabular}

Notes: ${ }^{\text {TT }}$ reatments were inhaled separately via OLO Respimat and TIO HandiHaler; bavailable only as abstract. I+2, replicate studies.

Abbreviations: AUC, area under the curve; BID, bis in die (twice daily); $\mathrm{FEV}_{1}$, forced expiratory volume in I second; IC, inspiratory capacity; PLA, placebo; SALM/FLU, salmeterol/fluticasone; SGRQ, St George's Respiratory Questionnaire (score); TDI, Transition Dyspnea Index; TIO/OLO, tiotropium-olodaterol fixed-dose combination; $\triangle R V$, change in $R V$ after treatment versus placebo; $\triangle F R C$, change in FRC after treatment versus placebo. 
RCTs is provided in Table 1. The majority of patients in the ANHELTO, VIVACITO, OTEMTO, TONADO, and ENERGITO studies belonged to GOLD stage II (50\%-72\%) or stage III $(27 \%-40 \%) \cdot{ }^{26-30}$ COPD stage IV patients were absent in the ENERGITO, MORACTO, and TORRACTO studies, ${ }^{29,31,32}$ whereas for the ANHELTO, OTEMTO, VIVACITO, and TONADO studies only $0.2 \%, 0.5 \%-1.5 \%$, $2 \%$, and $10 \%-12 \%$, respectively, were classified as GOLD stage IV. ${ }^{26-28,30}$ The distribution of COPD patients according to the new GOLD subgroups was available for two studies: in OTEMTO, 30\% of the patients belonged to GOLD subgroup A, 30\% to subgroup B, $15.3 \%$ to subgroup C, and $24.7 \%$ to subgroup D, whereas in TONADO $41.3 \%$ were classified as GOLD subgroups $\mathrm{A}$ and $\mathrm{B}$ and $58.7 \%$ as GOLD subgroups C and D. ${ }^{34,35}$

The percentage of patients on ICS varied between 9.6\% for ENERGITO and 34.8\%-41.9\% for OTEMTO, $35.8 \%-37.8 \%$ for ANHELTO, $41.1 \%$ for VIVACITO, and $45.1 \%-49.2 \%$ for TONADO. ${ }^{26,28-30}$ Between $0.2 \%$ and $11 \%$ of patients were on xanthines. ${ }^{26,27,29,36}$ Inhaled salbutamol was provided as rescue medication for use throughout these studies.

\section{Comparison between TIO/OLO 5/5 $\mu \mathrm{g}$ and placebo}

FDC TIO/OLO 5/5 $\mu \mathrm{g}$ was associated with clinically and statistically significant benefits over placebo for several measures of efficacy and HR-QoL (Tables 2 and 3).

\section{Pulmonary function}

TIO/OLO $5 / 5 \mu \mathrm{g}$ once daily was effective in improving pulmonary function in patients with COPD in one 6-week and two 12-week trials. ${ }^{26,28}$ Compared with placebo, dual bronchodilatation significantly improved the 0- to 24-hour weighted mean $\mathrm{FEV}_{1}$ by $280 \mathrm{~mL}$ and trough $\mathrm{FEV}_{1}$ by $160 \mathrm{~mL}$, as well as the $\mathrm{FEV}_{1}$ area under the curve (AUC) from 0 to 12 hours $\left(\mathrm{FEV}_{1} \mathrm{AUC}_{0-12}\right), \mathrm{FEV} \mathrm{AUC}_{12-24}$, and FEV $\mathrm{AUC}_{0-3}$ after 6 weeks. ${ }^{26}$ Similar observations were made for trough $\mathrm{FEV}_{1}(160 \mathrm{~mL})$ and $\mathrm{FEV}_{1} \mathrm{AUC}_{0-3}$ after 12 weeks of treatment in another study. ${ }^{28}$ All improvements exceeded the threshold of clinical significance, estimated to be $100-140 \mathrm{~mL}{ }^{37,38}$

\section{Symptoms}

TIO/OLO $5 / 5 \mu \mathrm{g}$ once daily was associated with statistically and clinically significant benefits in dyspnea relative to placebo. In OTEMTO 1 and 2, TIO/OLO 5/5 $\mu$ g significantly improved Mahler Transition Dyspnea Index (TDI) focal scores at 12 weeks compared with placebo by 2.05 and 1.2 units, respectively, ${ }^{28}$ exceeding the minimal clinically important difference (MCID) of $\geq 1$ unit defined for that variable. ${ }^{37,38}$ The overall number of responders was $53.9 \%$ after TIO/OLO $5 / 5 \mu \mathrm{g}$ and $26.2 \%$ after placebo. Consistent with these findings, significantly more patients on TIO/OLO $5 / 5 \mu \mathrm{g}$ than placebo recipients also reduced the use of rescue medication from three puffs/day to $1.8 \mathrm{puffs} /$ day. ${ }^{39}$

\section{Health-related quality of life}

Clinically and statistically significant differences were observed between once-daily TIO/OLO 5/5 $\mu \mathrm{g}$ and placebo for HR-QoL. St George's Respiratory Questionnaire (SGRQ) scores decreased by 4.89 units and 4.56 units compared with placebo in OTEMTO 1 and 2, respectively. ${ }^{28}$ The percentage of patients classified as SGRQ responders (defined as an improvement from baseline exceeding 4 units $)^{37,38}$

Table 2 Differences in TIO/OLO 5/5 $\mu$ g, TIO monotherapy, OLO monotherapy, and PLA for different spirometric end points derived from key clinical studies

\begin{tabular}{|c|c|c|c|c|}
\hline Study & $\mathrm{AUC}_{0-24} \mathrm{FEV}_{1}(\mathrm{~mL})$ & Peak $_{0-3}$ FEV $_{1}(\mathrm{~mL})$ & $\mathrm{AUC}_{0-3} \mathrm{FEV}_{1}(\mathrm{~mL})$ & Trough FEV,$(\mathrm{mL})$ \\
\hline \multicolumn{5}{|c|}{ TIO/OLO 5/5 $\mu \mathrm{g}$ vs PLA } \\
\hline Beeh et $\mathrm{al}^{26}$ & $\Delta=280$ & $4 I I$ vs 72 & & 201 vs -6 \\
\hline Singh et $\mathrm{al}^{28}$ & & & $\Delta=33 \mathrm{I}$ and $\Delta=299$ & $\Delta=162$ and $\Delta=166$ \\
\hline \multicolumn{5}{|c|}{ TIO/OLO $5 / 5 \mu \mathrm{g}$ vs TIO $5 \mu \mathrm{g}$} \\
\hline Beeh et $\mathrm{al}^{26}$ & $\Delta=110$ & $4 I I$ vs 300 & & 201 vs 122 \\
\hline Singh et $\mathrm{al}^{28}$ & & & $\Delta=\mathrm{I} \mid \mathrm{I}$ and $\Delta=\mathrm{I} 05$ & $\Delta=28$ and $\Delta=39$ \\
\hline Buhl et $\mathrm{al}^{27}$ & & & $\Delta=117$ and $\Delta=103$ & $\Delta=7 \mid$ and $\Delta=50$ \\
\hline \multicolumn{5}{|c|}{ TIO I8 $\mu \mathrm{g}+$ OLO $5 \mu \mathrm{g}^{\mathrm{a}}$ vs TIO I8 $\mu \mathrm{g}$} \\
\hline ZuWallack e & & & $\Delta=1 \mathrm{I} 7$ and $\Delta=106$ & $\Delta=60$ and $\Delta=40$ \\
\hline \multicolumn{5}{|c|}{ TIO/OLO $5 / 5 \mu \mathrm{g}$ vs OLO $5 \mu \mathrm{g}$} \\
\hline Beeh et $\mathrm{al}^{26}$ & $\Delta=1 \mathrm{I} 5$ & 41 I vs 291 & & 201 vs 109 \\
\hline Buhl et $\mathrm{al}^{27}$ & & & $\Delta=123$ and $\Delta=132$ & $\Delta=82$ and $\Delta=88$ \\
\hline
\end{tabular}

Note: ${ }^{a}$ Treatments inhaled separately via OLO Respimat and TIO HandiHaler.

Abbreviations: AUC, area under the curve; $\mathrm{FEV}_{1}$, forced expiratory volume in I second; PLA, placebo; TIO/OLO, tiotropium-olodaterol fixed-dose combination. 
Table 3 Differences in TIO/OLO 5/5 $\mu \mathrm{g}$, TIO monotherapy, OLO monotherapy, and PLA in key clinical studies, highlighting number of responders and number needed to treat

\begin{tabular}{|c|c|c|c|c|c|c|}
\hline Study & TDI & TDI responders $(\%)$ & NNT $(95 \% \mathrm{Cl})$ & SGRQ & SGRQ responders (\%) & NNT $(95 \% \mathrm{Cl})$ \\
\hline \multicolumn{7}{|c|}{ TIO/OLO 5/5 $\mu \mathrm{g}$ vs PLA } \\
\hline \multirow[t]{2}{*}{ Singh et $\mathrm{al}^{28}$} & 2.1 and 1.2 & 53.9 vs 26.2 & $4(3.1-4.2)$ & -4.89 and -4.59 & 53.1 vs 31.2 and & $5(3.8-5.7)$ and \\
\hline & & & & & 51.8 vs 32.6 & $6(4.2-6.6)$ \\
\hline \multicolumn{7}{|c|}{ TIO/OLO $5 / 5 \mu \mathrm{g}$ vs TIO $5 \mu \mathrm{g}$} \\
\hline \multirow[t]{2}{*}{ Singh et $\mathrm{al}^{28}$} & 0.6 and 0.6 & 53.9 vs 41 & $8(5.8-11.7)$ & -2.49 and -1.72 & 53.1 vs 41.7 and & $9(6.3-14.2)$ and \\
\hline & & & & & $5 \mathrm{I} .8 \mathrm{vs} 4 \mathrm{I} . \mathrm{I}$ & $10(6.6-15.7)$ \\
\hline Buhl et $\mathrm{al}^{27}$ & 0.4 & 54.9 vs 50.6 (NS) & 24 (NS) & -1.23 & 57.5 vs 48.7 & $12(7.6-22.5)$ \\
\hline \multicolumn{7}{|c|}{ TIO I8 $\mu \mathrm{g}+$ OLO $5 \mu \mathrm{g}$ vs TIO I8 $\mu \mathrm{g}$} \\
\hline ZuWallack e & & & & -1.85 & 49.3 vs 42.5 & $15(9-40)$ \\
\hline \multicolumn{7}{|c|}{ TIO/OLO $5 / 5 \mu \mathrm{g}$ vs OLO $5 \mu \mathrm{g}$} \\
\hline Buhl et $\mathrm{al}^{27}$ & 0.4 & 54.9 vs 48.2 & $15(9-42.9)$ & -1.69 & 57.5 vs 44.8 & $8(5.9-12)$ \\
\hline
\end{tabular}

Abbreviations: NNT, number needed to treat; Cl, confidence interval; NS, not significant; PLA, placebo; SGRQ, St George's Respiratory Questionnaire (score); TDI, Transition Dyspnea Index; TIO/OLO, tiotropium-olodaterol fixed-dose combination.

at 12 weeks increased from $31.9 \%$ in the placebo arm to $52.4 \%$ (full analysis) with TIO/OLO $5 / 5 \mu \mathrm{g}$ (Table 2), with an odds ratio of being a responder for $\mathrm{TIO} / \mathrm{OLO} 5 / 5 \mu \mathrm{g}$ versus placebo of approximately 2.5 (95\% confidence interval [CI] $1.6-3.8){ }^{28}$

\section{Markers of hyperinflation and exercise tolerance} $\mathrm{TIO} / \mathrm{OLO} 5 / 5 \mu \mathrm{g}$ was associated with reductions in FRC and residual volume (RV) at 2 hours 30 minutes and 22 hours 30 minutes postdose relative to placebo (Figure 1). Changes from baseline for FRC were $-547 \mathrm{~mL}$ after TIO/OLO 5/5 and $-52 \mathrm{~mL}$ after placebo at 2.5 hours postdose. Even at
22.5 hours postdose, the difference between TIO/OLO $5 / 5 \mu \mathrm{g}$ and placebo exceeded $300 \mathrm{~mL}$. These improvements in FRC and RV were mirrored by changes in inspiratory capacity (IC): $351 \mathrm{~mL}$ after TIO/OLO $5 / 5 \mu \mathrm{g}$ and $16 \mathrm{~mL}$ after placebo compared with baseline values 2.5 hours postdose. ${ }^{26}$ Differences between treatments still averaged $200 \mathrm{~mL} 22.5$ hours postdose and reached statistical significance. These beneficial effects of TIO/OLO $5 / 5 \mu \mathrm{g}$ on hyperinflation at rest were confirmed in three other placebo-controlled crossover studies. The MORACTO studies demonstrated that TIO/OLO 5/5 $\mu \mathrm{g}$ once daily improved IC by 244 and $265 \mathrm{~mL}$ after 6 weeks, whereas TORRACTO showed an IC increase of $234 \mathrm{~mL}$
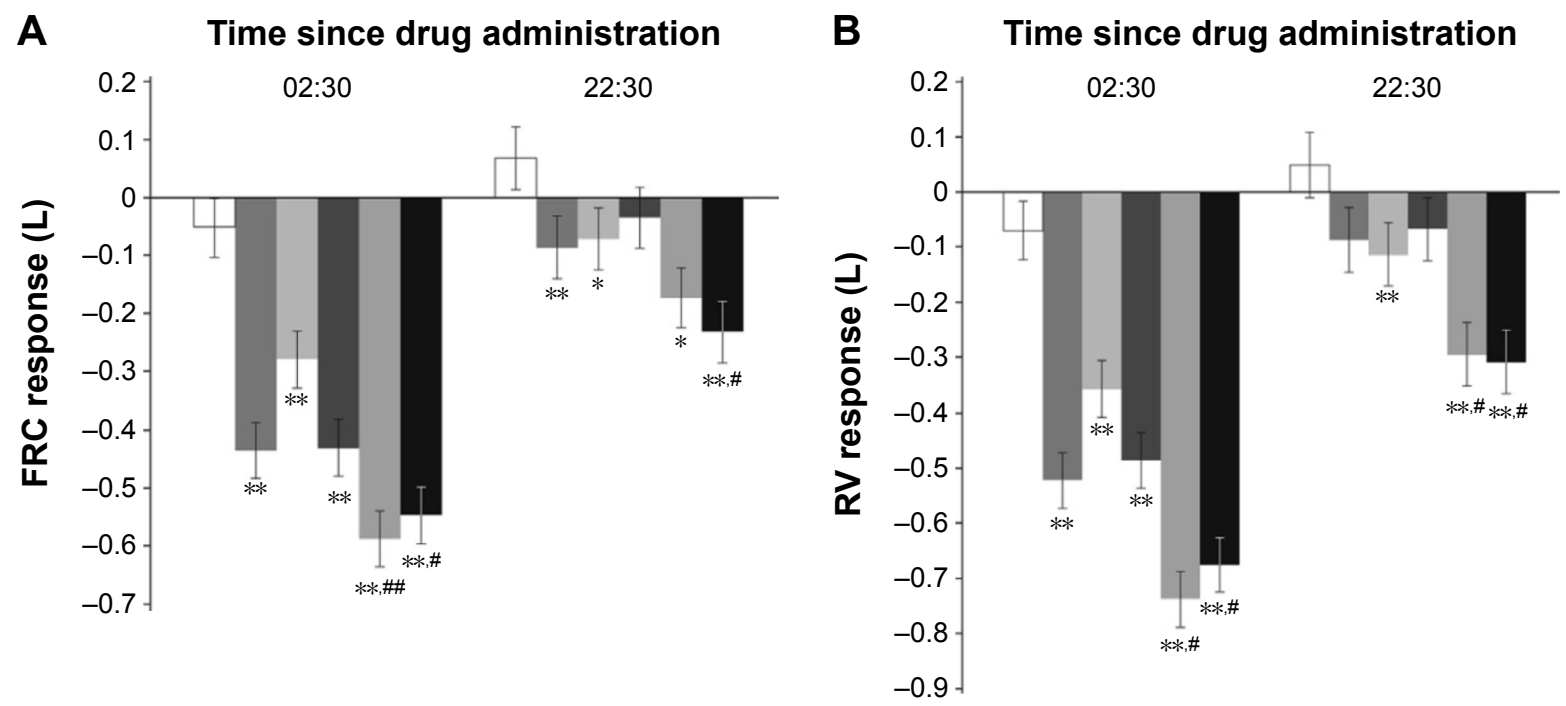

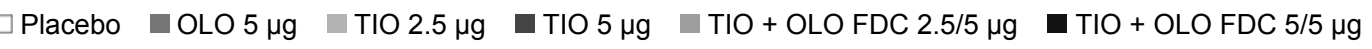

Figure I Adjusted mean FRC (A) and RV (B) responses at 6 weeks \pm SE, measured by body plethysmography at 2 hours 30 minutes (02:30) and 22 hours 30 minutes postdose.

Notes: ${ }^{* P}<0.05$ versus placebo; ${ }^{* * P}<0.000$ I versus placebo; ${ }^{\#}<0.05$ versus all monotherapies; ${ }^{\#} P<0.0$ I versus all monotherapies. Reproduced from Beeh $K M$, Westerman J, Kirsten AM, et al. The 24-h lung-function profile of once-daily tiotropium and olodaterol fixed-dose combination in chronic obstructive pulmonary disease. Pulm Pharmacol Ther. 20I5;32:53-59. ${ }^{26}$

Abbreviations: FRC, functional residual capacity; RV, residual volume; SE, standard error; OLO, olodaterol; TIO, tiotropium; FDC, fixed-dose combination. 
after a 12-week treatment with TIO/OLO 5/5 $\mu$ g. ${ }^{23,40,41}$ These gains in IC persisted during exercise and contributed to significantly improved exercise endurance upon treatment with TIO/OLO 5/5 $\mu$ g. Compared with placebo, endurance time during constant work-rate cycle ergometry increased by 79 and 54 seconds in MORACTO ${ }^{31}$ and 64 seconds in TORRACTO. ${ }^{32}$ Breathing discomfort at isotime was reduced in patients treated with $\mathrm{TIO} / \mathrm{OLO} 5 / 5 \mu \mathrm{g}$, with mean Borg scale values of 4.44 with TIO/OLO 5/5 $\mu \mathrm{g}$ and 5.14 with placebo. ${ }^{31}$ In that study, the endurance shuttle-walk test also increased by $21 \%$ with TIO/OLO $5 / 5 \mu \mathrm{g}$ at week 12 compared with placebo.

\section{Comparison between TIO/OLO 5/5 $\mu \mathrm{g}$ and TIO $5 \mu \mathrm{g}$ monotherapy}

For a variety of clinical endpoints, differences between TIO/OLO $5 / 5 \mu \mathrm{g}$ FDC and TIO $5 \mu \mathrm{g}$ monotherapy - both administered via the Respimat soft-mist inhaler - generally reached statistical significance in favor of dual bronchodilatation, without however reaching the threshold of clinical significance (Tables 2 and 3). However, we need to take into account the fact that thresholds of MCIDs have been established in the past by comparing a single active treatment with placebo. Whether the same thresholds of MCIDs should be applied when comparing dual combinations with their active monocomponents is still a matter of debate. ${ }^{38}$

\section{Pulmonary function}

Data from the VIVACITO trial showed that once-daily TIO/ OLO $5 / 5 \mu \mathrm{g}$ produced significant improvements in $\mathrm{FEV}_{1}$ $\mathrm{AUC}_{0-24}, \mathrm{FEV}_{1} \mathrm{AUC}_{0-12}$, and $\mathrm{FEV}_{1} \mathrm{AUC}_{12-24}$ compared with once-daily TIO $5 \mu \mathrm{g}$ monotherapy (Table 2). ${ }^{26}$ Moreover, TIO/OLO 5/5 $\mu \mathrm{g}$ also significantly improved $\mathrm{AUC}_{0-3} \mathrm{FEV}_{1}$ and trough $\mathrm{FEV}_{1}$ at the end of the study period compared with TIO $5 \mu \mathrm{g}$. Likewise, ANHELTO 1 and 2 showed that dual bronchodilatation also improved pulmonary function significantly more than once-daily monotherapy with TIO. ${ }^{30}$ In these two replicate studies, OLO $5 \mu \mathrm{g}$ was inhaled via the Respimat, while TIO $18 \mu \mathrm{g}$ (equivalent to TIO $5 \mu \mathrm{g}$ via Respimat) was administered via HandiHaler. In the OTEMTO 1 and 2 studies, statistically significant differences in favor of TIO/OLO $5 \mu \mathrm{g}$ were seen at the end of the study periods compared with TIO $5 \mu \mathrm{g}$ monotherapy. Differences ranged between 105 and $111 \mathrm{~mL}$ for peak $\mathrm{AUC}_{0-3}$ $\mathrm{FEV}_{1}$ and between 28 and $39 \mathrm{~mL}$ for trough $\mathrm{FEV}_{1} \cdot{ }^{28} \mathrm{Similar}$ findings were observed in TONADO, in which more than 5,000 patients were involved: ${ }^{27}$ statistically significant improvements were noted for both $\mathrm{AUC}_{0-3} \mathrm{FEV}_{1}$ and trough
$\mathrm{FEV}_{1}$ with TIO/OLO $5 \mu \mathrm{g}$ compared with TIO $5 \mu \mathrm{g}$ after 24 weeks (Table 2). These improvements in $\mathrm{FEV}_{1}$ persisted for 52 weeks. Responses in trough $\mathrm{FVC}$ and $\mathrm{AUC}_{0-3} \mathrm{FVC}$ to once-daily TIO/OLO $5 / 5 \mu \mathrm{g}$ and TIO $5 \mu \mathrm{g}$ were similar to those reported in other trials. ${ }^{28}$

\section{Symptoms and use of rescue medication}

As summarized in Table 3, TIO/OLO 5/5 $\mu \mathrm{g}$ differed significantly from TIO $5 \mu \mathrm{g}$ monotherapy in terms of alleviating symptoms of dyspnea, as measured by TDI at week 12, the mean difference equaling approximately 0.6 units in both OTEMTO studies. ${ }^{28}$ The overall number of responders on the TDI was $53.9 \%$ after TIO/OLO $5 \mu \mathrm{g}$ and $41 \%$ after TIO $5 \mu \mathrm{g}$, corresponding with a number needed to treat (NNT) of eight. ${ }^{39}$ TIO/OLO 5/5 $\mu \mathrm{g}$ also significantly lowered the use of rescue salbutamol more than TIO $5 \mu \mathrm{g}$ : 1.8 puffs/day for dual bronchodilatation versus 2.4 puffs/day for once-daily TIO $5 \mu \mathrm{g} .{ }^{39}$ TONADO showed comparable statistically significant differences between TIO/OLO 5/5 $\mathrm{g}$ and TIO $5 \mu \mathrm{g}$, with a difference in TDI of 0.36 units in favor of double bronchodilatation. In this study, daytime use of rescue salbutamol was $0.97 \mathrm{puffs} /$ day with TIO $5 \mu \mathrm{g}$ and $0.76 \mathrm{puffs} /$ day with TIO/OLO $5 / 5 \mu \mathrm{g}$, whereas the nighttime use of salbutamol was 1.69 and 1.24 puffs/day, respectively. ${ }^{27,40,41}$ ANHELTO had already previously demonstrated that the number of rescue-medication-free days increased by about $8 \%$ with the combination treatment compared with TIO monotherapy. ${ }^{30}$

\section{Health-related quality of life}

OTEMTO 1 and 2 demonstrated that overall improvements in SGRQ with TIO $5 \mu \mathrm{g}$ were small compared to placebo $(-2.4$ $[P<0.05]$ and -2.85 units [not significant] $)$ and did not reach the MCID. ${ }^{28}$ This contrasts with improvements of more than 4 units with TIO/OLO $5 / 5 \mu \mathrm{g}$ compared with placebo. The likelihood of becoming a responder for the SGRQ compared with baseline was $41.4 \%$ with TIO $5 \mu \mathrm{g}$ and $52.4 \%$ with TIO/OLO $5 / 5 \mu \mathrm{g}$, with an odds ratio of approximately 1.5 , corresponding with an NNT of nine to ten (Table 3). Similar observations were made in ANHELTO (Table 3). ${ }^{30}$ More pronounced clinically meaningful improvements in SGRQ total scores were reached in TONADO with TIO/OLO $5 / 5 \mu \mathrm{g}$ (-6.8 units) and TIO $5 \mu \mathrm{g}$ (-5.6 units) compared to baseline. ${ }^{27}$ The difference between TIO/OLO 5/5 $\mu \mathrm{g}$ and TIO $5 \mu \mathrm{g}$ (1.2 units) reached statistical significance but failed to reach the threshold of MCID. In that study, the number of participants exhibiting an MCID in HR-QoL increased compared with baseline from $48.7 \%$ with TIO $5 \mu \mathrm{g}$ to $57.5 \%$ with TIO/OLO 5/5, corresponding to an NNT of 12 . 


\section{Markers of hyperinflation and exercise tolerance}

Reductions in FRC and RV measured 2.5 and 22.5 hours after inhalation of TIO $5 \mu \mathrm{g}$ were smaller $(431 \mathrm{~mL})$ than those obtained with TIO/OLO $5 / 5 \mu \mathrm{g}(547 \mathrm{~mL})$. This difference corresponded to a $100 \mathrm{~mL}$ difference in increase in IC between TIO/OLO $5 / 5 \mu \mathrm{g}$ and TIO $5 \mu \mathrm{g} .{ }^{26}$ Similar differences (114 and $88 \mathrm{~mL}$ ) in improvement in IC were observed between TIO/OLO 5/5 and TIO 5 in two other 6-week studies, and these differences persisted during exercise. ${ }^{31}$ In the exercise studies, no differences were observed for endurance time or Borg score for dyspnea during constant work-rate cycle ergometry after 6 weeks between TIO $5 \mu \mathrm{g}$ and TIO/OLO 5/5. However, in a subgroup of severely hyperinflated COPD patients, statistically significant differences in endurance time during constant work rate were observed between TIO $5 \mu \mathrm{g}$ and TIO/OLO $5 / 5 \mu \mathrm{g}$ in favor of dual bronchodilatation. ${ }^{31}$

\section{Exacerbations}

Only correctly powered studies enrolling large number of COPD patients at high risk of exacerbations (based upon prior exacerbation history and severity of airflow obstruction) will elucidate the question of whether dual bronchodilatation is superior to TIO monotherapy for prevention of exacerbations. Such a study, DYNAGITO, comparing the effects of TIO/OLO $5 / 5 \mu \mathrm{g}$ and TIO $5 \mu \mathrm{g}$ and investigating as primary outcome the annualized rate of moderate-tosevere COPD exacerbations over 1 year, is ongoing and registered as NCT02296138 at ClinicalTrials.gov. Although the TONADO studies were not designed to assess this important issue, their 52-week duration was sufficient to explore the potential effects of the interventions on the occurrence of exacerbations. ${ }^{27}$ In TONADO, a moderate exacerbation was defined by the need for systemic steroids or antibiotics, whereas a severe exacerbation required hospitalization. In the combined data set, the percentage of patients with at least one moderate-to-severe COPD exacerbation was $27.7 \%$ for the TIO/OLO $5 / 5 \mu \mathrm{g}$ FDC and $28.8 \%$ with TIO $5 \mu \mathrm{g}$. Unexpectedly, the percentage of patients with at least one severe COPD exacerbation was $5.9 \%(\mathrm{n}=61)$ for $\mathrm{TIO} / \mathrm{OLO} 5 / 5 \mu \mathrm{g}$ and $4.5 \%(\mathrm{n}=47)$ for TIO $5 \mu \mathrm{g}$. These differences did not reach statistical significance..$^{27,42}$

\section{Comparison between TIO/OLO 5/5 $\mu \mathrm{g}$ and OLO $5 \mu \mathrm{g}$ monotherapy}

As in the comparison between once-daily TIO/OLO $5 / 5 \mu \mathrm{g}$ FDC and once-daily TIO $5 \mu \mathrm{g}$, differences between TIO/OLO $5 / 5 \mu \mathrm{g}$ FDC once-daily and OLO $5 \mu \mathrm{g}$ once-daily, both administered via the Respimat soft-mist inhaler, were generally statistically but not clinically significant in favor of dual bronchodilatation (Tables 2 and 3).

\section{Pulmonary function}

$\mathrm{FEV}_{1} \mathrm{AUC}_{0-24}, \mathrm{FEV}_{1} \mathrm{AUC}_{0-12}, \mathrm{FEV}_{1} \mathrm{AUC}_{12-24}, \mathrm{FEV}_{1} \mathrm{AUC}_{0-3}$, and trough $\mathrm{FEV}_{1}$ increased significantly after a 6-week treatment with once-daily TIO/OLO $5 / 5 \mu \mathrm{g}$ compared with oncedaily OLO $5 \mu \mathrm{g}$ monotherapy in VIVACITO ${ }^{26}$ (Table 1). Similar findings were observed in TONADO, which demonstrated statistically significant improvements in $\mathrm{FEV}_{1} \mathrm{AUC}_{0-3}$ and trough $\mathrm{FEV}_{1}$ for $\mathrm{TIO} / \mathrm{OLO} 5 \mu \mathrm{g}$ in comparison with OLO $5 \mu \mathrm{g}$, persisting for 52 weeks. Similar responses in trough FVC and $\mathrm{FVC} \mathrm{AUC}_{0-3}$ were also observed in that study. ${ }^{27}$

\section{Symptoms and use of rescue medication}

Statistically significant differences between TIO/OLO $5 / 5 \mu \mathrm{g}$ and OLO $5 \mu \mathrm{g}$ were observed in TONADO, reaching 0.42 units for the TDI in favor of double bronchodilatation $(P<0.005)$. Moreover, daytime use of rescue salbutamol was $0.87 \mathrm{puffs} /$ day with OLO $5 \mu \mathrm{g}$ and $0.76 \mathrm{puffs} /$ day with $\mathrm{TIO} / \mathrm{OLO} 5 / 5 \mu \mathrm{g}$, whereas nighttime use of salbutamol was 1.52 and 1.24 puffs/day, respectively..$^{27,40,41}$

\section{Health-related quality of life}

In TONADO, changes in SGRQ total scores compared with baseline with OLO $5 \mu \mathrm{g}$ reached -5.1 units (compared with -6.8 units after double bronchodilatation). The difference between TIO/OLO $5 / 5 \mu \mathrm{g}$ and OLO $5 \mu \mathrm{g}$ was thus 1.7 units, which did not reach the threshold of minimal clinical significance..$^{27}$ In that study, the number of responders on the SGRQ compared with baseline increased from $44.8 \%$ with OLO $5 \mu \mathrm{g}$ to $57.5 \%$ with TIO/OLO $5 / 5 \mu \mathrm{g}$, corresponding to an NNT of eight. ${ }^{27}$

\section{Markers of hyperinflation and exercise tolerance}

Reductions in FRC and RV versus baseline measured 2.5 hours after inhalation of OLO $5 \mu \mathrm{g}$ were smaller $(435 \mathrm{~mL})$ than those with TIO/OLO $5 / 5 \mu \mathrm{g}(547 \mathrm{~mL})$. Reciprocal increases in IC were $242 \mathrm{~mL}$ with OLO $5 \mu \mathrm{g}$ and $351 \mathrm{~mL}$ with TIO/OLO $5 / 5 \mu \mathrm{g} 2.5$ hours after inhalation. ${ }^{26}$ Differences in IC between TIO/OLO $5 / 5 \mu \mathrm{g}$ and OLO $5 \mu \mathrm{g}$ were similar in magnitude in two other 6-week studies (119 and $80 \mathrm{~mL})$ and these differences persisted during exercise. ${ }^{31,40,41}$ Endurance time during constant workrate cycle ergometry after TIO/OLO $5 / 5 \mu \mathrm{g}$ increased by 47 seconds in MORACTO 2, whereas no such increase was seen in MORACTO $1 .{ }^{31}$ 


\section{Exacerbations}

In the combined data set of TONADO, the percentage of patients with at least one moderate-to-severe COPD exacerbation was $27.7 \%$ for the TIO/OLO 5/5 $\mu \mathrm{g}$ FDC and 31.9\% with OLO $5 \mu \mathrm{g}$. As assessed by Kaplan-Meier estimates, the risk of a moderate-to-severe exacerbation was significantly lower with $\mathrm{TIO} / \mathrm{OLO} 5 / 5 \mu \mathrm{g}$ than with OLO $5 \mu \mathrm{g}$, with a risk ratio of 0.83 (95\% CI 0.71-0.99). Indices for severe exacerbations were comparable between TIO/OLO $5 / 5 \mu \mathrm{g}$ FDC and OLO $5 \mu \mathrm{g}$, since the percentage of patients with at least one severe COPD exacerbation was $5.9 \%(\mathrm{n}=61)$ for $\mathrm{TIO} / \mathrm{OLO}$ $5 / 5 \mu \mathrm{g}$ and $5.4 \%(\mathrm{n}=56)$ for OLO $5 \mu \mathrm{g} .{ }^{27,42}$

\section{Comparison between TIO/OLO 5/5 $\mu \mathrm{g}$ and salmeterol-fluticasone propionate}

In a 6-week trial that enrolled more than 200 patients with COPD, the effects of dual bronchodilatation and two strengths of SALM/FLU twice daily were compared with regard to the $\mathrm{FEV}_{1} \mathrm{AUC}_{0-12}$ (primary end point), $\mathrm{FEV}_{1}$ $\mathrm{AUC}_{12-24}, \mathrm{FEV}_{1} \mathrm{AUC}_{0-24}, \mathrm{FEV}_{1}$ peak $_{0-3}$, and trough $\mathrm{FEV}_{1}$. Treatment with TIO/OLO $5 / 5 \mu \mathrm{g}$ once daily produced significantly greater improvements in pulmonary function than SALM/FLU 50/500 $\mu \mathrm{g}$ and 50/250 $\mu \mathrm{g}$ twice daily after 6 weeks. ${ }^{29}$ Greater improvements in $\mathrm{FEV}_{1} \mathrm{AUC}_{0-12}$ of approximately $125 \mathrm{~mL}$ were observed with TIO/OLO 5/5 $\mu \mathrm{g}$ compared with either dose of SALM/FLU. Treatment with TIO/OLO $5 / 5 \mu \mathrm{g}$ once daily improved $\mathrm{FEV}_{1}$ values with approximately $85 \mathrm{~mL}$ over the full 24-hour dosing interval compared with SALM/FLU.

\section{Efficacy according to the COPD subgroups}

A post hoc analysis of TONADO shows that the bronchodilating properties of TIO/OLO $5 / 5 \mu \mathrm{g}$ remained preserved in more severe stages of COPD. ${ }^{43}$ Post hoc analyses have also been performed for both OTEMTO and TONADO in an attempt to differentiate effects of treatments between the GOLD COPD subgroups A-D. It should however be pointed out that these studies were designed and initiated before the 2011 GOLD update. ${ }^{1}$ In OTEMTO, TIO/OLO was more effective than placebo at improving $\mathrm{FEV}_{1} \mathrm{AUC}_{0-3}$, trough $\mathrm{FEV}_{1}$, SGRQ total score, and TDI focal score in all GOLD A-D subgroups. When comparing TIO/OLO $5 / 5 \mu \mathrm{g}$ to TIO $5 \mu \mathrm{g}$ monotherapy, $\mathrm{FEV}_{1} \mathrm{AUC}_{0-3}$, trough $\mathrm{FEV}_{1}$, and TDI improved in all GOLD A-D subgroups. For $\mathrm{FEV}_{1} \mathrm{AUC}_{0-3}$, the level of significance was reached for all subgroups, whereas statistical significance was reached only for trough $\mathrm{FEV}_{1}$ in the $\mathrm{A}, \mathrm{B}$, and $\mathrm{D}$ subgroups and for TDI only in the
C subgroup. Likewise, treatment effects differed between subgroups for SGRQ total score, improvements being most evident in the GOLD B subgroup. ${ }^{35}$ In TONADO, numerically greater responses in both $\mathrm{FEV}_{1} \mathrm{AUC}_{0-3}$ and trough $\mathrm{FEV}_{1}$ were demonstrated in patients classified as GOLD A/B compared to patients classified as GOLD C/D, with statistically significant differences between TIO/OLO $5 / 5 \mu \mathrm{g}$ and both monotherapies in each subgroup. ${ }^{34}$

\section{Safety issues}

Overall, the TIO/OLO FDC appears to be well tolerated and devoid of important side effects. In OTEMTO, the incidence of adverse events (AEs) was higher in the placebo than in the actively treated groups, leading to more frequent discontinuation of the study in the placebo group. ${ }^{28}$ In VIVACITO, however, AEs were balanced among the different treatment groups. ${ }^{26}$ In the combined analysis of the 52-week TONADO, the overall incidence of AEs was $74 \%, 73.3 \%$, and $76.6 \%$ for TIO/OLO, TIO, and OLO, respectively. Most of these were of mild or moderate severity, without differences between treatments. Treatment-related AEs were reported in 7.1\%, $6.1 \%$, and $6.6 \%$ of patients on TIO/OLO, TIO, and OLO, and serious AEs (SAEs) in $16.4 \%, 16.7 \%$, and $17.4 \%$ of patients, respectively. The most common SAEs in TIO/OLO, TIO, and OLO recipients were of respiratory origin: COPD exacerbations $(6.9 \%, 6.3 \%$, and $6.5 \%$, respectively) and pneumonias $\left(1.7 \%, 0.9 \%\right.$, and $1.4 \%$, respectively). ${ }^{27}$ Withdrawals from the study because of AEs were noted in $7.4 \%, 9 \%$, and $9.9 \%$ of patients, respectively. ${ }^{27}$ The incidence of cardiovascular SAEs was $1.8 \%, 1.8 \%$, and $1.4 \%$ and that of cerebrovascular SAEs $0.5 \%, 0.5 \%$, and $0.6 \%$ in the respective groups, without significant differences between the treatment groups. ${ }^{27}$ More detailed reports on tolerability and AEs of TIO/OLO can be found elsewhere. ${ }^{22-25,44,45}$

\section{Comparisons between tiotropium/ olodaterol $5 / 5 \mu \mathrm{g}$ fixed-dose combination and other LAMA/ LABA fixed-dose combinations}

Since none of the currently licensed LAMA/LABA FDCs have been compared in head-to-head RCTs, they can only be weighed against each other by indirect comparisons. Such comparisons are difficult to perform, and their conclusions should be interpreted with great caution. Indeed, important between-study differences exist on how classical outcomes, such as reversibility of airway obstruction, QoL, exercise tolerance, dyspnea, and rate of exacerbations, are assessed and expressed. Moreover, study design, distribution of COPD 
severity within the study population, exacerbation history, symptoms, concomitant ICS use, age and sex, degree of hyperinflation, and reversibility, as well as baseline exercise capacity and knowledge of inhaler technique, may affect the outcome of a pharmacological intervention with bronchodilators to a certain extent. Likewise, seasonal effects and (even more) the Hawthorne effect (ie, beneficial effects observed in RCTs due to the fact that patients who are participating in an RCT change their behavior, such as improved adherence to maintenance treatment and better inhaler technique) may further complicate comparisons between studies.

In order to weigh the existing LABA/LAMA formulations among one other, data from placebo-controlled studies may be completed with a "network meta-analysis", which allows the combination of trials involving different sets of treatments, to end up with an integrated and structured single analysis. Data are now available comparing the effects of four LABA/LAMA FDCs for such end points as trough FEV , TDI, and QoL, using that specific technique.

\section{Placebo-controlled studies}

Despite some limitations, placebo-controlled trials allow comparison to a certain extent of the magnitude of clinical effects of other LAMA/LABA FDCs and TIO/OLO 5/5 $\mu \mathrm{g}$ with a common comparator - placebo. However, placebocontrolled trials with LAMA/LABA FDCs other than $\mathrm{TIO} / \mathrm{OLO}$ are limited in number (Table 4). Overall, it appears that the magnitude of the effect observed with currently marketed FDCs is strikingly similar to those seen with TIO/ OLO for trough FEV 1 , TDI, and HR-QoL (Table 2). ${ }^{46-49}$ Likewise, the reported differences between GLY/IND $50 / 110 \mu \mathrm{g}$ and placebo for lung volumes $(-520 \mathrm{~mL}$ for FRC and $340 \mathrm{~mL}$ for IC at 1 hour postdose) are strikingly similar to the changes seen 2.5 hours postdose with $\mathrm{TIO} /$ OLO $5 / 5 \mu \mathrm{g} .{ }^{50}$ In two replicate studies assessing the effects of UMEC/VIL $62.5 / 25 \mu \mathrm{g}$ on lung volumes, differences from placebo were -238 and $-351 \mathrm{~mL}$ for trough FRC, -295 and $-466 \mathrm{~mL}$ for trough $\mathrm{RV}$, and 238 and $316 \mathrm{~mL}$ for IC 3 hours postdose. ${ }^{51}$

\section{Trough FEV,}

In a recently published network meta-analysis, ${ }^{22}$ Calzetta et al used clinical data from more than 23,000 patients to compare the effects of four LABA/LAMA FDCs with monocomponents. They demonstrated that TIO/OLO $5 / 5 \mu \mathrm{g}$ increased trough $\mathrm{FEV}_{1}$ by $55 \mathrm{~mL}$ (95\% CI 46-64) compared to monocomponents, whereas UMEC/VIL 62.5/25 $\mu \mathrm{g}$, ACL/ FORM 400/12 $\mu \mathrm{g}$, and GLY/IND 50/110 $\mu \mathrm{g}$ increased trough $\mathrm{FEV}_{1}$ by $84 \mathrm{~mL}$ (95\% CI 66-102), $46 \mathrm{~mL}$ (95\% CI 18-74), and $89 \mathrm{~mL}(95 \% \mathrm{CI} 76-103)$ compared to monotherapy, respectively. For GLY/IND, efficacy did not depend on the regimen of administration (once daily, $92 \mathrm{~mL}$ [95\% CI 73-110]; twice daily, $91 \mathrm{~mL}$ [95\% CI: 66-115]). Surprisingly, the lower dose of UMEC/VIL 62.5/25 $\mu \mathrm{g}$ elicited a greater increase in trough $\mathrm{FEV}_{1}$ when compared with UMEC/ VIL 125/25 $\mu \mathrm{g}$ (95 mL [95\% CI 73-117] versus $72 \mathrm{~mL}$ [95\% CI 44-100], respectively), although the difference was not statistically significant. For none of the FDCs did differences between dual bronchodilatation and monocomponents exceed the generally accepted MCID for $\mathrm{FEV}_{1}$ of $100 \mathrm{~mL}^{37,38}$ The network meta-analysis presented by Calzetta et al suggested that a gradient of effectiveness among the different drug combinations may exist, with UMEC/VIL slightly exceeding the effects of GLY/IND $(-12 \mathrm{~mL})$, TIO/OLO $(-30 \mathrm{~mL})$, and ACL/FORM (-49 mL), though statistically significant differences among the FDCs were not observed. ${ }^{22}$ Moreover,

Table 4 Differences between several LAMA/LABA fixed-dose combinations and PLA

\begin{tabular}{|c|c|c|c|c|c|c|}
\hline Study & $\mathbf{n}$ & Trough FEV $(\mathbf{m L})$ & SGRQ & TDI & $\mathrm{FRC/IC} \mathrm{(mL)}$ & ET (s) \\
\hline \multicolumn{7}{|c|}{ GLY/IND I I $0 / 50 \mu \mathrm{g}$ vs PLA } \\
\hline Bateman et $\mathrm{al}^{46}$ & 2,144 & $\Delta=200$ & $\Delta=-3$ & $\Delta=\mathrm{I} . \mathrm{I}$ & & \\
\hline Beeh et $\mathrm{a}^{50}$ & 84 & & & & $\Delta=-520 / \Delta=340$ & $\Delta=60$ \\
\hline \multicolumn{7}{|c|}{ UMEC/VIL 62.5/25 $\mu \mathrm{g}$ vs PLA } \\
\hline Donohue et $\mathrm{al}^{47}$ & 1,536 & $\Delta=167$ & $\Delta=-5.5$ & $\Delta=1.2$ & & \\
\hline Maltais et $\mathrm{al}^{51}$ & 308 & & & & $-/ \Delta \approx 250$ & $\Delta=69.4$ \\
\hline Maltais et $\mathrm{al}^{51}$ & 349 & & & & $-/ \Delta \approx 400$ & $\Delta=21.9$ \\
\hline \multicolumn{7}{|c|}{ ACL/FORM $400 / 12 \mu \mathrm{g}$ BID vs PLA } \\
\hline D’Urzo et $\mathrm{al}^{48}$ & 1,692 & -35 vs 94 & -6.57 vs -2.21 & 2 vs 0.6 & & \\
\hline Singh et $\mathrm{a}^{49}$ & ।,729 & $\Delta=143$ & -8.3 vs -6.5 & 2.5 vs 1.2 & & \\
\hline
\end{tabular}

Abbreviations: ACL/FORM, aclidinium-formoterol fixed-dose combination; BID, bis in die (twice daily); ET, endurance time (during constant work-rate cycle ergometry); $\mathrm{FEV}_{1}$, forced expiratory volume in I second; FRC, functional residual capacity; GLY/IND, glycopyrronium-indacaterol fixed-dose combination; IC, inspiratory capacity; LABA, long-acting $\beta_{2}$-agonist; LAMA, long-acting muscarinic antagonist; PLA, placebo; SGRQ, St George's Respiratory Questionnaire (score); TDI, Transition Dyspnea Index; UMEC/VIL, umeclidinium-vilanterol fixed-dose combination. 
none of the comparative studies included in that analysis was double dummy or head to head.

\section{Transition Dyspnea Index}

For all the investigated LAMA/LABA combinations, statistically significant improvements in TDI were observed compared with monocomponents. However, the overall differences in TDI between LAMA/LABA FDC and monotherapies were small and did not exceed 0.5 units. ${ }^{22}$ Compared with monotherapies, differences between $\mathrm{TIO} / \mathrm{OLO}$ and other LAMA/LABA FDCs were even smaller ( 0.3 units). The NNT to increase the TDI focal score by $\geq 1$ unit was (compared with a LAMA) nine to 12 for TIO/OLO $5 / 5 \mu \mathrm{g},{ }^{27,28}$ nine for GLY/IND, ${ }^{52}$ and 20 for UMEC/VIL 62.5/25 $\mu \mathrm{g} .{ }^{53}$

\section{Health-related quality of life}

Overall, the investigated LAMA/LABA combinations reduced the SGRQ score significantly compared with monocomponents, with differences ranging between 1.3 and 1.5 units compared with monotherapies for the different LAMA/ LABA FDCs. In this regard, differences between TIO/OLO and other LAMA/LABA FDCs did not exceed 0.2 units. Analysis of data reported in individual studies showed that the NNT to decrease the SGRQ score by $\geq 4$ in patients already treated with TIO $5 \mu \mathrm{g}$ ranged between nine and 12 for TIO/ OLO 5/5 (Table 3), between eleven and 16 for GLY/IND, ${ }^{54,55}$ and 14 for UMEC/VIL. ${ }^{56}$ The ACL/FORM formulation did not significantly influence the ratio of responder patients. ${ }^{57}$

\section{Hyperinflation and exercise}

Network meta-analyses have thus far not addressed the effects of LAMA/LABA combinations on other clinically relevant outcomes, such as hyperinflation or exercise tolerance. The few available studies showed that reductions in FRC and RV measured 60 minutes after inhalation of GLY/ IND $62.5 / 25 \mu \mathrm{g}$ were larger (520 and $520 \mathrm{~mL}$, respectively) than those obtained with TIO $18 \mu \mathrm{g}$ inhaled via HandiHaler (400 and $410 \mathrm{~mL}$, respectively), leading to a reciprocal increase in IC of $150 \mathrm{~mL}$ with GLY/IND 62.5/25 $\mu \mathrm{g}$ compared with TIO $18 \mu \mathrm{g} .{ }^{50}$ These differences are in the same order of magnitude as the differences between TIO/ OLO $5 / 5 \mu \mathrm{g}$ and TIO $5 \mu \mathrm{g}$. Reductions in hyperinflation, seen with GLY/IND 62.5/25 $\mu \mathrm{g}$, were not translated into prolongations in endurance time on the cyclo-ergometer, which were similar to those obtained with TIO $18 \mu \mathrm{g}$ via HandiHaler. The effects of inhaled UMEC/VIL 62.5/25 $\mu \mathrm{g}$ and UMEC $62.5 \mu \mathrm{g}$ on endurance time during exercise were inconsistent: ${ }^{51}$ compared with placebo, endurance time increased by 69 (95\% CI 24-114) and 22 (95\% CI -14 to 58) seconds with UMEC/VIL 62.5/25 $\mu \mathrm{g}$ and by 25 (95\% CI -41 to 91 ) and 26.5 (95\% CI -26 to 79 ) seconds with UMEC $62.5 \mu \mathrm{g}$, respectively.

\section{Exacerbations}

Research is ongoing to determine whether the TIO/OLO 5/5 $\mu \mathrm{g}$ FDC is superior to TIO $5 \mu \mathrm{g}$ in preventing COPD exacerbations. However, a few studies comparing other existing LAMA/LABA FDCs with a LAMA have already attempted to clarify the potential place of dual bronchodilatation in this regard.

In one study, the effects of GLY/IND 50/110 $\mu \mathrm{g}$, TIO $18 \mu \mathrm{g}$ (via HandiHaler), and GLY $50 \mu \mathrm{g}$ on exacerbations were investigated during a 64-week trial in COPD patients who all belonged to stage III/IV (GOLD B and D, new classification). ${ }^{55}$ Interestingly, inclusion in that study was restricted to patients with a history of at least one COPD exacerbation requiring treatment with antibiotics and/or systemic corticosteroids within the previous year. GLY/IND $50 / 110 \mu \mathrm{g}$ significantly reduced the rate of all (mild, moderate, and severe) exacerbations by $14 \%$ compared with TIO $18 \mu \mathrm{g}$ via HandiHaler and by $15 \%$ compared with GLY 50 $\mu \mathrm{g}$. The effect was largely driven by the reduction in mild exacerbations (about three per year), since the incidence of moderate and severe exacerbations was similar among the three groups. ${ }^{55}$ In that study, the NNT was 19 to prevent one exacerbation with GLY/IND 50/110 $\mu \mathrm{g}$ compared with TIO and 25 compared with GLY. ${ }^{55,58}$

The FLAME study, a second 52-week-long study comparing the effects of GLY/IND 50/110 $\mu \mathrm{g}$ once daily with SALM/FLU 50/500 $\mu \mathrm{g}$ twice daily on the rate of COPD exacerbations, showed that dual bronchodilatation was more effective in reducing not only all (mild, moderate, and severe) exacerbations but also the number of both moderate and severe COPD exacerbations, ${ }^{53,59}$ with an NNT of 17 for moderate and severe exacerbations. Importantly, FLAME excluded all COPD patients with a history of asthma, concomitant allergic rhinitis, or very pronounced blood eosinophilia (>600 eosinophils $/ \mu \mathrm{L})$.

Studies comparing the effects of UMEC/VIL and UMEC on exacerbations ${ }^{47,53,60,61}$ have not yielded conclusive results, possibly because of insufficient duration and less stringent patient selection.

\section{Perspective: when to add a LABA to a LAMA in COPD?}

The previous sections clearly demonstrate that TIO/OLO $5 / 5 \mu \mathrm{g}$, formulated in the Respimat soft-mist inhaler, 
substantially improves trough $\mathrm{FEV}_{1}$, TDI scores, markers of dynamic hyperinflation, and HR-QoL. Differences reach or even exceed the MCID for FEV ${ }_{1}$, TDI, and HR-QoL compared with placebo. TIO/OLO $5 / 5 \mu \mathrm{g}$ also statistically improves spirometric variables, TDI scores, HR-QoL, and markers of hyperinflation compared to TIO $5 \mu \mathrm{g}$. However, the MCID between dual bronchodilatation and monotherapy is generally not reached.

Although efforts to grade and compare the effects of all available LAMA/LABA FDCs should be interpreted with caution, placebo-controlled studies and a network meta-analysis comparing the effects of TIO/OLO $5 / 5 \mu \mathrm{g}$ with other available LAMA/LABA FDCs allow us to conclude that their overall effects on pulmonary function, HR-QoL, and TDI are comparable in magnitude. Therefore, if differences were to exist between different LABA/LAMA FDCs, these differences would be small and probably not clinically relevant. Possibly, the currently assessed end points and techniques used to investigate their effects are not sensitive enough to pick up the clinical impact of undeniable differences that prevail between available LAMA/LABA FDCs in terms of pharmacological characteristics of the individual LAMA and LABA components (eg, onset and duration of action, maximum effect and potency, receptor selectivity, lipophilicity, dissociation half-life, serum half-life, and metabolism issues). ${ }^{7,62,63}$ Only head-to-head comparisons can solve this issue.

The potential beneficial effects of dual bronchodilatation over monotherapies in the prevention of COPD exacerbations require further investigation, however. The limited data available on $\mathrm{TIO} / \mathrm{OLO} 5 / 5 \mu \mathrm{g}$ suggest that dual bronchodilatation was superior to OLO $5 \mu \mathrm{g}$ but not to TIO $5 \mu \mathrm{g}$ in preventing moderate-to-severe exacerbations, a finding that is in line with a recent network meta-analysis in which the effects of several LABA/LAMA combinations were reviewed. ${ }^{45}$ Differences between TIO/OLO $5 / 5 \mu \mathrm{g}$ and TIO $5 \mu \mathrm{g}$ or OLO $5 \mu \mathrm{g}$ do not appear to exist for severe exacerbations, ${ }^{27}$ and Oba et al came to the same conclusions for all LABAs, LAMAs, and LAMA/LABA FDCs. ${ }^{45}$ The apparently intriguing observation that long-acting bronchodilators prevent better against mild and moderate exacerbations than against severe exacerbations may be attributed to several factors. First, the specific actions of long-acting bronchodilators might not affect the frequency of exacerbations per se, but through reducing breathlessness may increase the threshold at which a given patient will consider his/her worsening sufficiently severe to be labeled an exacerbation. ${ }^{64}$ Secondly, LAMA-containing combinations could further enhance that protective effect in reducing mucus hypersecretion, although hard evidence is still lacking to support this contention. Thirdly, the efficacy of active treatments in preventing severe exacerbations (requiring hospitalization) is difficult to prove in classical RCTs, where COPD patients are closely monitored (encompassing regular study visits and daily monitoring of symptoms and spirometry). Due to this intensive proactive monitoring in classical RCTs, COPD patients experiencing increased symptoms of an ensuing exacerbation are treated promptly (with an increase in inhaled bronchodilators, oral corticosteroids, and/or antibiotics), preventing further clinical deterioration and thereby the need for hospital admissions. Therefore, and due to exclusion of COPD patients with significant comorbidities, the incidence of hospitalizations due to COPD exacerbations are rare events in classical RCTs.

In the past, it was deemed unlikely that bronchodilating drugs would affect the acute inflammatory response to respiratory infections or exposure to airway irritants accompanying more severe exacerbations, which give rise to symptoms that eventually require treatment with anti-inflammatory drugs. ${ }^{64}$ This hypothesis has however been recently challenged by the FLAME study, which concluded that GLY/IND 50/110 $\mu \mathrm{g}$ once daily provided better protection than a SALM/FLU 50/500 $\mu \mathrm{g}$ FDC twice daily against mild, moderate, and severe exacerbations in COPD GOLD stage $B$ and $D$ patients. ${ }^{47,53,60,61}$ It is crucially important to note that all COPD patients who might potentially have experienced beneficial effects from an ICS treatment (previous asthma, asthma COPD overlap syndrome, increased blood eosinophilia, and allergic rhinitis) were completely excluded from that study, maximizing in this way the effect of dual bronchodilatation. Unfortunately, this study did not address the issue of whether dual bronchodilatation is superior to a LAMA in preventing severe exacerbations in that subgroup of COPD patients. $^{59}$

TIO/OLO $5 / 5 \mu \mathrm{g}$ reduced markers of hyperinflation, such as FRC, compared to monotherapies, the difference exceeding $200 \mathrm{~mL} 22$ hours after inhalation. The exact meaning of a $200 \mathrm{~mL}$ reduction in FRC is unknown, since its MCID has not been determined so far. At that time point, the effects of the monotherapies on FRC (Figure 1) have almost completely disappeared. ${ }^{27,51}$ Despite its substantial effects on dynamic hyperinflation, dual bronchodilatation does not increase endurance time during constant work exercise compared to monotherapies, a feature that TIO/OLO 5/5 $\mu \mathrm{g}$ shares with other LAMA/LABA FDCs. ${ }^{31,32,50,51}$ The reasons for the additional improvement in markers of hyperinflation seen with dual bronchodilatation are not translated into additional gains in endurance time are unclear. Patient selection 
may definitely play a role, since TIO/OLO $5 / 5 \mu \mathrm{g}$ enhances endurance time during constant work exercise in severely hyperinflated patients ${ }^{31}$ compared to monotherapies. Another possibility is that a ventilatory-limited COPD patient may become limited by peripheral muscle weakness once treated with one bronchodilator. In such a case, the addition of a second long-acting bronchodilator will not affect exercise endurance, unless the prevailing limiting factor, the peripheral muscle weakness, is treated. Studies comparing the effects of dual bronchodilatation with monotherapy on the outcome of a pulmonary rehabilitation program could answer this question. Interestingly, the impact of optimization of bronchodilatation on the outcome of pulmonary rehabilitation has been nicely demonstrated previously with TIO monotherapy. ${ }^{18}$

American, European, and Japanese regulatory authorities have licensed a number of LAMA/LABA FDCs to treat COPD patients for symptom relief and pulmonary function improvement. Currently, the question remains unanswered as to whether all patients with COPD or only some phenotypes within the COPD-patient group should be treated with a LAMA/LABA FDC. Indeed, the current GOLD guidelines recommend maintenance therapy with either a LAMA or LABA in symptomatic patients with moderate or severe COPD. When patients are not adequately controlled with a single long-acting bronchodilator, combining a LAMA with a LABA may be beneficial. An ICS/LABA combination is an option for maintenance treatment in COPD patients who are at high risk of exacerbations, ${ }^{1}$ especially if these exacerbations require treatment with oral corticosteroid courses only (without antibiotics). However, ICS/LABA combinations are often prescribed to patients who do not qualify for this criterion. ${ }^{65,66}$

It is tempting to initiate a treatment with a LABA/ LAMA FDC in every new symptomatic COPD patient, since dual bronchodilatation yields superior effects compared to monotherapies and will result in MCIDs in the domains of pulmonary function, dyspnea, and HR-QoL compared with placebo. However, a substantial number of patients do well with monotherapy, such that this surplus in bronchodilatation does not always lead to better QoL, improved endurance time, or fewer exacerbations in every single patient. ${ }^{45}$ Indeed, differences between dual bronchodilatation and monotherapy generally remain below the currently accepted MCIDs for a number of domains. It has thus been suggested that the current thresholds used to define an MCID when comparing two active treatments be redefined. ${ }^{38}$

Another option is to perform a responder analysis in studies assessing the effects of long-acting bronchodilators. This demonstrates that certain patients already reach the
MCID with one bronchodilator, and that this proportion may be increased by selective prescription of dual bronchodilatation in patients not responding to monotherapy. ${ }^{38}$ The proposed strategy combines a personalized approach of the patient with an optimal use of health care resources, and should remain the strategy of choice, at least as long as price differences between dual bronchodilatation and monotherapies remain substantial. Moreover, this is in line with a general rule in medicine, which says not to treat patients with two medicines if satisfactory results may be obtained with only one medicine. Nevertheless, responder analyses and NNT calculations reported in clinical trials with COPD should be approached with caution, since a Hawthorne effect appears to be present in many trials, minimizing the effect of the intervention. ${ }^{38}$ Therefore, the currently available efficacy data from classical RCTs should be completed with effectiveness data obtained in real-life studies (ie, pragmatic trials and observational studies), which may yield more realistic data in this regard. Importantly, whereas the aforementioned classical RCTs had high internal validity thanks to randomization and double-blind design, their external validity might be limited due to a (highly) selected COPD patient population that is not representative of the full spectrum of COPD patients seen in clinical practice. This has implications for real-life effectiveness (and comparative effectiveness), as well as long-term safety in a real-world setting, since many patients COPD with comorbidities (asthma, cardiovascular disease, heart failure) and polypharmacy are excluded from classical RCTs. ${ }^{67}$

If the evidence is currently lacking to initiate dual bronchodilatation in every COPD patient at the time of diagnosis, clinical studies suggest that the threshold to prescribe dual bronchodilatation should be low in patients who remain symptomatic under monotherapy, in highly breathless or hyperinflated COPD patients, in those included in a pulmonary rehabilitation program, and in those patients in COPD GOLD subgroups B and D who comply with the stringent inclusion and exclusion criteria of the recently published FLAME study.

To support early treatment of COPD patients with dual bronchodilatation, additional studies should be conducted to demonstrate its disease-modifying effect. The protocol that should be followed to conduct such an early intervention study was proposed some years ago. ${ }^{68}$ Interestingly, a prespecified analysis of the UPLIFT trial showed that TIO significantly reduced the rate of decline of postbronchodilator $\mathrm{FEV}_{1}$ relative to control in patients with COPD stage II, a feature that was not present in more severe COPD stages. ${ }^{69}$ 


\section{Conclusion}

In conclusion, TIO/OLO $5 / 5 \mu \mathrm{g}$ is a LAMA/LABA FDC formulated in a Respimat soft-mist inhaler that has been thoroughly investigated in over 10,000 COPD patients. Its effects on a variety of relevant clinical end points, including lung function, symptoms (TDI), and QoL (SGRQ), are comparable to other LAMA/LABA FDCs. In a COPD population at relatively low risk of exacerbations, TIO/OL $5 / 5 \mu \mathrm{g}$ significantly reduced the rate of exacerbations compared with OLO $5 \mu \mathrm{g}$ monotherapy, but not compared to TIO $5 \mu \mathrm{g}$ monotherapy. Larger long-term studies in COPD patients at high risk of exacerbations are required and ongoing to investigate whether TIO/OLO $5 / 5 \mu \mathrm{g}$ is also superior to TIO $5 \mu \mathrm{g}$ monotherapy in reducing moderate and severe COPD exacerbations. Clinical studies with TIO/OLO $5 / 5 \mu \mathrm{g}$ and other LAMA/LABA FDCs support their use in COPD patients who remain symptomatic and patients who frequently exacerbate and exhibit some well-defined COPD phenotypes.

\section{Acknowledgments}

The authors thank Annie Wittewrongel and Anny Mattelaer for expert technical help and writing assistance.

\section{Disclosure}

The authors report no conflicts of interest in this work.

\section{References}

1. Global Initiative for Chronic Obstructive Lung Disease. Global Strategy for the Diagnosis, Management, and Prevention of Chronic Obstructive Pulmonary Disease. Bethesda (MD): GOLD; 2016.

2. Vestbo J, Edwards LD, Scanlon PD, et al. Changes in forced expiratory volume in 1 second over time in COPD. $N$ Engl J Med. 2011; 365(13):1184-1192.

3. Lange P, Celli B, Agusti A, et al. Lung-function trajectories leading to chronic obstructive pulmonary disease. $N$ Engl J Med. 2015; 373(2):111-122.

4. Vestbo J, Lange P. Natural history of COPD: focusing on change in $\mathrm{FEV}_{1}$. Respirology. 2016;21(1):34-43.

5. Miller A, Raskin JM. The natural history of COPD: confirming and going beyond Fletcher and Peto. Eur Respir J. 2014;44(2):280-283.

6. Decramer M, Janssens W, Miravitlles M. Chronic obstructive pulmonary disease. Lancet. 2012;379(9823):1341-1351.

7. Cazzola M, Page CP, Calzetta L, Matera MG. Pharmacology and therapeutics of bronchodilators. Pharmacol Rev. 2012;64(3):450-504.

8. Calzetta L, Matera MG, Cazzola M. Pharmacological interaction between LABAs and LAMAs in the airways: optimizing synergy. Eur J Pharmacol. 2015;761:168-173.

9. Cazzola M, Molimard M. The scientific rationale for combining long-acting $\beta_{2}$-agonists and muscarinic antagonists in COPD. Pulm Pharmacol Ther. 2010;23(4):257-267.

10. Calverley PM, Burge PS, Spencer S, Anderson JA, Jones PW. Bronchodilator reversibility testing in chronic obstructive pulmonary disease. Thorax. 2003;58(8):659-664.

11. Cooper CB. The connection between chronic obstructive pulmonary disease symptoms and hyperinflation and its impact on exercise and function. Am J Med. 2006;119(10 Suppl 1):21-31.
12. Tantucci C, Duguet A, Similowski T, Zelter M, Derenne JP, Milic-Emili J. Effect of salbutamol on dynamic hyperinflation in chronic obstructive pulmonary disease patients. Eur Respir J. 1998;12(4):799-804.

13. O'Donnell DE, Flüge T, Gerken F, et al. Effects of tiotropium on lung hyperinflation, dyspnoea and exercise tolerance in COPD. Eur Respir J. 2004;23(6):832-840.

14. O'Donnell DE, Voduc N, Fitzpatrick M, Webb KA. Effect of salmeterol on the ventilatory response to exercise in chronic obstructive pulmonary disease. Eur Respir J. 2004;24(1):86-94.

15. Donohue JF. Combination therapy for chronic obstructive pulmonary disease: clinical aspects. Proc Am Thorac Soc. 2005;2(4):272-281.

16. Gross NJ. Tiotropium bromide. Chest. 2004;126(6):1946-1953.

17. Karner C, Chong J, Poole P. Tiotropium versus placebo for chronic obstructive pulmonary disease. Cochrane Database Syst Rev. 2012;(7):CD009285.

18. Casaburi R, Kukafka D, Cooper CB, Witek TJ Jr, Kesten S. Improvement in exercise tolerance with the combination of tiotropium and pulmonary rehabilitation in patients with COPD. Chest. 2005;127(3): 809-817.

19. Chong J, Karner C, Poole P. Tiotropium versus long-acting $\beta$-agonists for stable chronic obstructive pulmonary disease. Cochrane Database Syst Rev. 2012;(9):CD009157.

20. Vogelmeier C, Hederer B, Glaab T, et al. Tiotropium versus salmeterol for the prevention of exacerbations of COPD. N Engl J Med. 2011; 364(12):1093-1103.

21. Decramer ML, Chapman KR, Dahl R, et al. Once-daily indacaterol versus tiotropium for patients with severe chronic obstructive pulmonary disease (INVIGORATE): a randomised, blinded, parallel-group study. Lancet Respir Med. 2013;1(7):524-533.

22. Calzetta L, Rogliani P, Matera MG, Cazzola M. A systematic review with meta-analysis of dual bronchodilation with LAMA/LABA for the treatment of stable COPD. Chest. 2016;149(5):1181-1196.

23. Dhillon S. Tiotropium/olodaterol: a review in COPD. Drugs. 2016; 76(1):135-146.

24. Mosley JF, Smith LL, Dutton BN. Tiotropium bromide/olodaterol (Stiolto Respimat): once-daily combination therapy for the maintenance of COPD. P T. 2016;41(2):97-102.

25. Deeks ED. Olodaterol: a review of its use in chronic obstructive pulmonary disease. Drugs. 2015;75(6):665-673.

26. Beeh KM, Westerman J, Kirsten AM, et al. The 24-h lung-function profile of once-daily tiotropium and olodaterol fixed-dose combination in chronic obstructive pulmonary disease. Pulm Pharmacol Ther. 2015; 32:53-59.

27. Buhl R, Maltais F, Abrahams R, et al. Tiotropium and olodaterol fixeddose combination versus mono-components in COPD (GOLD 2-4). Eur Respir J. 2015;45(4):969-979.

28. Singh D, Ferguson GT, Bolitschek J, et al. Tiotropium + olodaterol shows clinically meaningful improvements in quality of life. Respir Med. 2015;109(10):1312-1319.

29. Beeh KM, Derom E, Echave-Sustaeta J, et al. The lung function profile of once-daily tiotropium and olodaterol via Respimat is superior to that of twice-daily salmeterol and fluticasone propionate via Accuhaler (ENERGITO study). Int J Chron Obstruct Pulmon Dis. 2016; 11:193-205

30. ZuWallack R, Allen L, Hernandez G, Ting N, Abrahams R. Efficacy and safety of combining olodaterol Respimat and tiotropium HandiHaler in patients with COPD: results of two randomized, doubleblind, active-controlled studies. Int J Chron Obstruct Pulmon Dis. 2014;9:1133-1144.

31. O'Donnell D, Casaburi R, De Sousa D, et al. Effects of 6 weeks' treatment with once-daily tiotropium and olodaterol fixed-dose combination on inspiratory capacity and exercise endurance in patients with COPD: The Moracto ${ }^{\mathrm{TM}}$ studies [ATS abstract]. Am J Respir Crit Care Med. 2015;191:A3972.

32. Maltais F, Iturri JB, Kirsten AM, et al. Effects of 12 weeks of once-daily tiotropium and olodaterol fixed-dose combination on exercise endurance in patients with COPD. Eur Respir J. 2014;44 Suppl 58:238. 
33. Aalbers R, Maleki-Yazdi MR, Hamilton A, et al. Randomized, doubleblind, dose-finding study for tiotropium when added to olodaterol, administered via the Respimat inhaler in patients with chronic obstructive pulmonary disease. Adv Ther. 2015;32(9):809-822.

34. Buhl R, Abrahams R, Grönke L, Voss F, Flezar M, Ferguson GT. Tiotropium + Olodaterol fixed-dose combination therapy provides lung-function benefits compared with Tiotropium alone in patients with GOLD A/B and C/D chronic obstructive pulmonary disease: post hoc analyses of two 1-year studies. Pneumologie. 2016;70:219.

35. Singh D, Gaga M, Schmidt O, et al. Effects of tiotropium + olodaterol versus tiotropium or placebo by COPD disease severity and previous treatment history in the OTEMTO studies. Respir Res. 2016; 17(1):73.

36. Casaburi R, Mahler DA, Jones PW, et al. A long-term evaluation of once-daily inhaled tiotropium in chronic obstructive pulmonary disease. Eur Respir J. 2002;19(2):217-224.

37. Cazzola M, MacNee W, Martinez FJ, et al. Outcomes for COPD pharmacological trials: from lung function to biomarkers. Eur Respir J. 2008;31(2):416-469.

38. Jones PW, Beeh KM, Chapman KR, Decramer M, Mahler DA, Wedzicha JA. Minimal clinically important differences in pharmacological trials. Am J Respir Crit Care Med. 2014;189(3):250-255.

39. Singh D, Ferguson G, Bolitschek J, et al. Tiotropium + olodaterol fixeddose combination shows clinically meaningful improvements in quality of life versus placebo. Eur Respir J. 2015;46 Suppl 59:PA2958.

40. [No authors listed]. Spiolto Respimat 2.5 microgram $/ 2.5$ microgram, inhalation solution (tiotropium and olodaterol). 2015. Available from: http:// mri.medagencies.org/download/NL_H_3157_001_PARSummary.pdf. Accessed October 15, 2016.

41. [No authors listed]. Spiolto Respimat 2.5 microgram $/ 2.5$ microgram, inhalation solution [summary of product characteristics]. 2016. Available from: http://mri.medagencies.org/download/NL_H_3157_001_ FinalPI.pdf. Accessed October 15, 2016.

42. Derom E, Flezar M, Grönke L, Voss F, Buhl R. Effect of tiotropium + olodaterol therapy on COPD exacerbations in the Tonado studies. Am J Respir Crit Care Med. 2016;193:A6805.

43. Ferguson GT, Fležar M, Korn S, et al. Efficacy of tiotropium + olodaterol in patients with chronic obstructive pulmonary disease by initial disease severity and treatment intensity: a post hoc analysis. Adv Ther. 2015;32(6):523-536.

44. Halpin DM, Dahl R, Hallmann C, Mueller A, Tashkin D. Tiotropium HandiHaler and Respimat in COPD: a pooled safety analysis. Int $J$ Chron Obstruct Pulmon Dis. 2015;10:239-259.

45. Oba Y, Sarva ST, Dias S. Efficacy and safety of long-acting $\beta$-agonist/ long-acting muscarinic antagonist combinations in COPD: a network meta-analysis. Thorax. 2016;71(1):15-25.

46. Bateman ED, Ferguson GT, Barnes N, et al. Dual bronchodilation with QVA149 versus single bronchodilator therapy: the SHINE study. Eur Respir J. 2013;42(6):1484-1494.

47. Donohue JF, Singh D, Munzu C, Kilbride S, Church A. Magnitude of umeclidinium/vilanterol lung function effect depends on monotherapy responses: results from two randomised controlled trials. Respir Med. 2016;112:65-74.

48. D'Urzo AD, Rennard SI, Kerwin EM, Mergel V, Leselbaum AR, Caracta CF. Efficacy and safety of fixed-dose combinations of aclidinium bromide/formoterol fumarate: the 24-week, randomized, placebocontrolled AUGMENT COPD study. Respir Res. 2014;15:123.

49. Singh D, Jones PW, Bateman ED, et al. Efficacy and safety of aclidinium bromide/formoterol fumarate fixed-dose combinations compared with individual components and placebo in patients with COPD (ACLIFORM-COPD): a multicentre, randomised study. BMC Pulm Med. 2014;14:178.

50. Beeh KM, Korn S, Beier J, et al. Effect of QVA149 on lung volumes and exercise tolerance in COPD patients: the BRIGHT study. Respir Med. 2014;108(4):584-592.
51. Maltais F, Singh S, Donald AC, et al. Effects of a combination of umeclidinium/vilanterol on exercise endurance in patients with chronic obstructive pulmonary disease: two randomized, double-blind clinical trials. Ther Adv Respir Dis. 2014;8(6):169-181.

52. Mahler DA, Decramer M, D'Urzo A, et al. Dual bronchodilation with QVA149 reduces patient-reported dyspnoea in COPD: the BLAZE study. Eur Respir J. 2014;43(6):1599-1609.

53. Donohue JF, Maleki-Yazdi MR, Kilbride S, Mehta R, Kalberg C, Church A. Efficacy and safety of once-daily umeclidinium/vilanterol $62.5 / 25 \mathrm{mcg}$ in COPD. Respir Med. 2013;107(10):1538-1546.

54. Frampton JE. QVA149 (indacaterol/glycopyrronium fixed-dose combination): a review of its use in patients with chronic obstructive pulmonary disease. Drugs. 2014;74(4):465-488.

55. Wedzicha JA, Decramer M, Ficker JH, et al. Analysis of chronic obstructive pulmonary disease exacerbations with the dual bronchodilator QVA149 compared with glycopyrronium and tiotropium (SPARK): a randomised, double-blind, parallel-group study. Lancet Respir Med. 2013;1(3):199-209.

56. Maleki-Yazdi MR, Kaelin T, Richard N, Zvarich M, Church A. Efficacy and safety of umeclidinium/vilanterol $62.5 / 25 \mathrm{mcg}$ and tiotropium $18 \mathrm{mcg}$ in chronic obstructive pulmonary disease: results of a 24-week, randomized, controlled trial. Respir Med. 2014;108(12):1752-1760.

57. Medic G, Lindner L, van der Weijden M, Karabis A. Efficacy and safety of aclidinium/formoterol versus tiotropium in COPD: results of an indirect treatment comparison. Adv Ther. 2016;33(3):379-399.

58. Rodrigo GJ, Plaza V. Efficacy and safety of a fixed-dose combination of indacaterol and glycopyrronium for the treatment of COPD: a systematic review. Chest. 2014;146(2):309-317.

59. Wedzicha JA, Banerji D, Chapman KR, et al. Indacaterol-glycopyrronium versus salmeterol-fluticasone for COPD. N Engl J Med. 2016;374(23): 2222-2234

60. Celli B, Crater G, Kilbride S, et al. Once-daily umeclidinium/ vilanterol 125/25 $\mu \mathrm{g}$ in COPD: a randomized, controlled study. Chest. 2014;145(5):981-991.

61. Decramer M, Anzueto A, Kerwin E, et al. Efficacy and safety of umeclidinium plus vilanterol versus tiotropium, vilanterol, or umeclidinium monotherapies over 24 weeks in patients with chronic obstructive pulmonary disease: results from two multicentre, blinded, randomised controlled trials. Lancet Respir Med. 2014;2(6):472-486.

62. Cazzola M, Beeh KM, Price D, Roche N. Assessing the clinical value of fast onset and sustained duration of action of long-acting bronchodilators for COPD. Pulm Pharmacol Ther. 2015;31:68-78.

63. Sentellas S, Ramos I, Alberti J, et al. Aclidinium bromide, a new, longacting, inhaled muscarinic antagonist: in vitro plasma inactivation and pharmacological activity of its main metabolites. Eur J Pharm Sci. 2010;39(5):283-290.

64. Vestbo J, Lange P. Prevention of COPD exacerbations: medications and other controversies. ERJ Open Res. 2015;1(1):00011.

65. Roche N, Pribil C, Van Ganse E, et al. Real-life use of fluticasone propionate/salmeterol in patients with chronic obstructive pulmonary disease: a French observational study. BMC Pulm Med. 2014;14:56.

66. Price D, West D, Brusselle G, et al. Management of COPD in the UK primary-care setting: an analysis of real-life prescribing patterns. Int $J$ Chron Obstruct Pulmon Dis. 2014;9:889-904.

67. Lahousse L, Verhamme KM, Stricker BH, Brusselle GG. Cardiac effects of current treatments of chronic obstructive pulmonary disease. Lancet Respir Med. 2016;4(2):149-164.

68. Decramer M, Cooper CB. Treatment of COPD: the sooner the better? Thorax. 2010;65(9):837-841.

69. Decramer M, Celli B, Kesten S, Lystig T, Mehra S, Tashkin DP. Effect of tiotropium on outcomes in patients with moderate chronic obstructive pulmonary disease (UPLIFT): a prespecified subgroup analysis of a randomised controlled trial. Lancet. 2009;374(9696):1171-1178. 
International Journal of COPD

\section{Publish your work in this journal}

The International Journal of COPD is an international, peer-reviewed journal of therapeutics and pharmacology focusing on concise rapid reporting of clinical studies and reviews in COPD. Special focus is given to the pathophysiological processes underlying the disease, intervention programs, patient focused education, and self management protocols.

This journal is indexed on PubMed Central, MedLine and CAS. The manuscript management system is completely online and includes a very quick and fair peer-review system, which is all easy to use. Visit http://www.dovepress.com/testimonials.php to read real quotes from published authors 